\title{
Ecomarketing na Web como Estratégia Competitiva de Empresas Turísticas em Parnaíba (PI)
}

\section{Ecomarketing on the Web as a Competitive Strategy for Tourism Companies in Parnaíba (PI, Brazil)}

\author{
Mayara Maia Ibiapina, Thaís Mayara Paes de Lima, \\ André Riani Costa Perinotto
}

\section{RESUMO}

A crescente preocupação da sociedade a respeito de questões ambientais está desencadeando certa pressão nas organizações. Cobram-se práticas responsáveis e rejeitam as agressões ambientais, estimulando a busca de alternativas ambientalmente corretas. Aliados a essa realidade surge um "novo" turista, com escolhas ambientalmente responsáveis e que preferem montar seus próprios roteiros de viagem utilizando a internet como base para suas pesquisas. Percebe-se então uma ligação importante entre as novas tecnologias e o Ecomarketing no desenvolvimento do turismo, assim, esse artigo surge da falta de estudos sobre 0 uso de estratégias de Marketing ecológico nas empresas turísticas de Parnaíba-PI e suas divulgações utilizando os recursos das novas tecnologias buscando investigar inicialmente os websites das empresas turísticas de Parnaíba para divulgação de seus serviços analisando a existência do uso de Ecomarketing nos mesmos. Espera-se com isso que esse trabalho contribua para uma visão ambientalmente responsável nas empresas turísticas de Parnaíba, aliando as preocupações ambientais com estratégia de marketing que influenciam positivamente no produto, preço, distribuição e promoção de seus serviços e estimule a maior visibilidade das empresas turísticas da cidade de Parnaíba na Web. Como metodologia, foram utilizados levantamento bibliográfico e estatístico e pesquisa exploratória com observação informal e aplicação de questionários cujas perguntas buscavam investigar se empresários e gestores conhecem as estratégias ecológicas. A partir do estudo proposto, identificou-se um despreparo das empresas no uso das tecnologias e no aproveitamento do Ecomarketing para desenvolver tanto seus negócios quanto o turismo local.

PALAVRAS-CHAVE: Ecomarketing; Estratégia Competitiva; Parnaíba; Websites. 


\section{ABSTRACT}

Ecotourism The social growing concern about environmental issues is sparking some pressure on organizations, charging responsible practices and rejecting environmental aggression, stimulating the search for environmentally right alternatives. Allied to this reality comes a "new" tourist with environmentally responsible choices who prefer to build their own travel itineraries using the internet as a basis for their research. Therefore, it becomes an important link between new technologies and the Eco Marketing in tourism development, so this article arises from the lack of studies on the use of environmental marketing strategies in tourist companies of Parnaíba and advertises using the resources of the new technologies in order to initially investigate the websites of tourism enterprises of Parnaíba (PI, Brazil) to publicize their services by analyzing the existence of using Eco Marketing in them. Hoping this work contributes to an environmentally responsible vision in tourist business of Parnaíba, combining environmental concerns with marketing strategy that positively influence the product, price, distribution and promotion of their services and encourage greater visibility of tourism enterprises of Parnaíba on the internet. The methodology used with bibliographic and statistical survey and exploratory research with informal observation and questionnaires whose questions aimed to investigate if business owners and managers really know the ecological strategies. From the proposed study, was identified a lack of preparation of companies in the use of technology and the use of Eco Marketing to develop both their companies and local tourism.

KEYWORDS: Ecomarketing; Strategy Competitive; Parnaíba; Websites.

\section{Introdução}

A cidade de Parnaíba está localizada no litoral do Piauí, à 354 km de Teresina capital do Estado, próximo a uma grande variedade de áreas naturais com praias, dunas, manguezais, ilhas e rios, com destaque ao Delta do Parnaíba, caracterizado por ser o único Delta em mar aberto das Américas. Esses aspectos evidenciam um grande potencial para a prática de Ecoturismo diversificado e exótico, seguindo a tendência mundial de conservação ambiental.

Segundo Motta e Oliveira (2007), existe uma crescente preocupação da sociedade a respeito de questões ambientais, assim a nova palavra em questão é: sustentabilidade, desencadeando certa pressão nas organizações, sendo inadmissível, que agressões ambientais sejam causadas, cobrando ações empresariais responsáveis e estimulando a busca de alternativas ambientalmente corretas.

Nesse sentido as empresas turísticas da cidade de Parnaíba devem perceber no perfil de um ecoturista, a preocupação com a responsabilidade ambiental. Além disso, essas empresas devem se preocupar em conservar essas áreas naturais pois são sua fonte de renda e razão de existência, ou seja, elas precisam incorporar ações de gestão ambiental em suas práticas para sobreviver. 
Para Molina (2001), o turismo transformou-se em uma atividade econômica de grande importância no planeta observando-se os números de deslocamentos, os empregos gerados, o seu impacto na Balança de Pagamentos, no Produto Nacional, bem como o montante de investimentos e gastos públicos ou privados que propicia além da possibilidade de desenvolvimento das comunidades e dos indivíduos, assim, existe uma ligação entre turismo e ecologia, uma vez que o processo de globalização pode levar os turistas a procurar novos destinos com maior qualidade ambiental ele defende a formação de uma consciência ambiental na sociedade, que estimulou o nascimento de novas gerações de visitantes, que ele chama de "novo turista", que passa de um turista poluidor a um turista mais consciente.

$\mathrm{Na}$ consequência do surgimento de empresas mais responsáveis o Ecomarketing ou Marketing Verde se alia a essas organizações na tentativa de elaborar e divulgar produtos para atender a uma nova demanda com necessidades de consumo de produtos menos agressivos possíveis, ao passo que torna o turismo uma atividade com menos impactos negativos a sociedade e ao meio ambiente. Desse modo entende-se que o Ecomarketing:

\begin{abstract}
Marketing verde, termo utilizado a primeira vez em 1997, é a prática administrativa na qual a empresa estrategicamente inclui a variável ambiental na sua imagem, agregando valor de responsável ambiental ou ecologicamente correta. Marketing verde, Ecomarketing, marketing sustentável, selo verde, gestão ambiental, entre outros termos recém adotados, são indicadores de um novo paradigma na esfera empresarial (FELIX, 2011 apud VIDAL, 2012, p. 31).
\end{abstract}

Uma ferramenta de divulgação de estratégias de Ecomarketing é a web, cada vez mais as pessoas preferem montar seus próprios roteiros e utilizam a internet como base para suas pesquisas. Percebe-se, então, uma ligação importante da internet e do Ecomarketing para um melhor desenvolvimento do turismo, esse artigo surge da falta de estudos sobre o uso de estratégias de Marketing ecológico nas empresas turísticas de Parnaíba e suas divulgações em Websites.

O objetivo do trabalho foi investigar o uso de sites pelas empresas turísticas de Parnaíba para divulgação de seus serviços analisando a existência do uso de Ecomarketing nas práticas empresariais. Espera-se que esse estudo contribua para uma visão ambientalmente responsável nas empresas turísticas de Parnaíba/PI, aliando as preocupações ambientais com estratégia de marketing que influenciam positivamente no produto, preço, distribuição e promoção de seus serviços, desse modo estimulando a maior visibilidade das empresas turísticas desse destino turístico na internet.

Como metodologia, foram utilizados levantamento bibliográfico e estatístico e pesquisa exploratória que foi realizada em dois momentos. No primeiro momento foi definido a população da pesquisa através do Programa Federal do Ministério do Turismo - Cadastur (Brasil, s/d) que faz um inventário de empresas relacionadas com Turismo, nele estão cadastradas 18 agências de turismo e 20 meios de hospedagens, foi feito uma 
investigação em todas as empresas cadastradas observando três informações: se o site foi encontrado, se o site está atualizado e se possui forte, pouca ou nenhuma presença de Ecomarketing.

No segundo momento, foi aplicado um questionário com cinco questões numa amostra de seis agências de turismo e seis meios de hospedagens cadastrados no Cadastur, procurando escolher aquelas que possuíam sites mais estruturados. As questões abordadas são: O gestor da empresa conhece o termo Ecomarketing ou Marketing Ecológico? A empresa tem um setor de marketing definido? A empresa utiliza estratégias de Ecomarketing? Se "sim" quais? Quais as mídias a empresa utiliza para divulgação de seus serviços? As perguntas buscavam investigar se empresários e gestores conhecem as estratégias ecológicas.

\title{
Websites: ferramentas de comunicação turística
}

A internet é uma ferramenta bastante valiosa na divulgação de destinos turísticos, é o veículo de comunicação mais utilizado pelos turistas na decisão do destino a visitar proporcionando um maior número de informações como: atrativos turísticos, empresas turísticas, endereços, infraestrutura, vias de acesso, entre outras, além das imagens persuasivas do local que são fatores determinantes na escolha do turista. Para Nielsen (2002, p. 39) "A internet (ou 'Net') é, sem dúvida, um dos avanços mais excitantes do mundo da comunicação de massa".

\begin{abstract}
$\mathrm{Na}$ internet, há vários endereços que auxiliam o viajante a planejar sua viagem, informam sobre aeroportos, consulados, embaixadas, como aproveitar milhagem, como obter vistos, checar descontos de hotéis e pousadas. Há ainda inúmeras reportagens sobre destinos para os mais variados tipos de público, sugestão de roteiros, aluguel de imóveis para a temporada, guias, enfim, uma enorme diversidade de informações que auxiliará o turista na escolha do seu destino (DIAS; CASSAR, 2005, p. 230).
\end{abstract}

A importância da internet para as viagens turísticas fica evidenciada nos dados estatísticos do Ministério do Turismo (BRASIL, 2009), que realizou uma pesquisa com 2.322 pessoas pelo Instituto Vox Populi, onde os entrevistados eram brasileiros maiores de 18 anos e eram clientes atuais ou potenciais, essa pesquisa apontou que $79,5 \%$ dos turistas organizam suas viagens por conta própria e 39,1\% utilizam a internet como fonte de informações. Isso mostra que a internet tem grande influência nas escolhas dos turistas e que é uma eficiente ferramenta para empresas divulgarem seus serviços e diferenciais, como ações de Ecomarketing, por exemplo.

Devido esse relativo crescimento do uso da internet, os websites vêm se tornando uma ferramenta indispensável para as empresas turísticas, seja elas de pequeno, médio ou grande porte, possibilitando uma comunicação mais direta com o cliente, mostrando ao consumidor o diferencial do seu produto/serviço, além de promover a localidade. Para isso, os websites devem ter conteúdo atraente e original e, acima de tudo, conhecer o seu 
público, assim ele poderá desenvolver estratégias de marketing voltadas para o segmento escolhido. De acordo com Amor (apud TOMIKAWA, 2009, p.68) "os sites são formas de organizar as informações existentes e, conforme o modo como tais informações são organizadas, pode-se defini-lo quanto a sua função ou às características de seu conteúdo".

O Website é um espaço de disponibilização de conteúdo (texto, fotos, animações gráficas, sons e vídeos), de empresas ou pessoas. O website tem como principal objetivo organizar a informação de modo lógico e coerente, estruturando uma hierarquia para que todo o conteúdo seja entendido e acessado com facilidade (AMOR apud TOMIKAWA, 2009).

Além da internet, outros canais são utilizados para promover uma localidade como jornais, televisão, folhetos, revistas, etc. $\mathrm{Na}$ Tabela 1 podemos visualizar os principais canais de comunicação, apresentando suas vantagens e desvantagens.

Tabela 1: perfis dos principais tipos de mídia.

Table 1: profiles of the main media types.

\begin{tabular}{|c|c|c|}
\hline Meio & Vantagens & Desvantagens \\
\hline Jornais & $\begin{array}{l}\text { Flexibilidade; boa cobertura do mercado local; } \\
\text { ampla aceitação e alta credibilidade. }\end{array}$ & $\begin{array}{l}\text { Vida curta; má qualidade de reprodução de } \\
\text { fotos. }\end{array}$ \\
\hline Televisão & $\begin{array}{l}\text { Combina imagem, som, movimento; atraente para } \\
\text { os sentidos; provoca muita atenção e apresenta } \\
\text { um alto grau de penetração. }\end{array}$ & $\begin{array}{l}\text { Custo absoluto elevado; há menos } \\
\text { seletividade de público (exceto os canais } \\
\text { pagos, que têm público altamente seletivo). }\end{array}$ \\
\hline Mala-direta & $\begin{array}{l}\text { Seletividade de público; flexibilidade; sem } \\
\text { concorrência com anúncios dentro do mesmo } \\
\text { meio; personalização. }\end{array}$ & $\begin{array}{l}\text { Custo relativamente alto; e dependendo da } \\
\text { relação de endereços, há um baixo retorno. }\end{array}$ \\
\hline $\begin{array}{l}\text { Telefone } \\
\text { (telemarketing) }\end{array}$ & $\begin{array}{l}\text { Possui as mesmas vantagens da mala-direta; } \\
\text { acrescenta um toque pessoal. }\end{array}$ & $\begin{array}{l}\text { O uso excessivo do telemarketing em } \\
\text { determinado público-alvo, de mais alto } \\
\text { poder aquisitivo, tem desgastado o veículo. }\end{array}$ \\
\hline Rádio & $\begin{array}{l}\text { Ampla utilização, pode ser utilizado com } \\
\text { seletividade geográfica; de baixo custo. }\end{array}$ & $\begin{array}{l}\text { Somente apresentação auditiva; prende } \\
\text { menos a atenção que a TV; exposição } \\
\text { passageira. }\end{array}$ \\
\hline Revistas & $\begin{array}{l}\text { Alta seletividade geográfica e demográfica; cre- } \\
\text { dibilidade e prestígio; reprodução de alta quali- } \\
\text { dade; vida longa; boa comunicação com leitores. }\end{array}$ & $\begin{array}{l}\text { Longo tempo de compra de anúncios } \\
\text { publicitários. }\end{array}$ \\
\hline Outdoors & $\begin{array}{l}\text { Flexibilidade; exposição repetida; baixo custo; } \\
\text { pouca concorrência. }\end{array}$ & $\begin{array}{l}\text { Não há seletividade de público; limitações } \\
\text { criativas. }\end{array}$ \\
\hline Folhetos & $\begin{array}{l}\text { Baixo custo; versatilidade; fácil de carregar; pode } \\
\text { ser considerado como parte da embalagem do } \\
\text { produto turístico. }\end{array}$ & $\begin{array}{l}\text { Folhetos mal elaborados embalam mal o } \\
\text { produto turístico. }\end{array}$ \\
\hline $\begin{array}{l}\text { Internet } \\
\text { (webmarketing) }\end{array}$ & $\begin{array}{l}\text { Baixo custo; versatilidade; seletividade de público; } \\
\text { personalização. }\end{array}$ & $\begin{array}{l}\text { Seu uso excessivo tem causado reprovação } \\
\text { em determinados públicos que empregam } \\
\text { meios de defesa contra esse tipo de mídia. }\end{array}$ \\
\hline
\end{tabular}

Fonte: Adaptado de Kotler, Heider e Rein (apud DIAS; CASSAR, 2005, p.224).

Source: Adapted of Kotler, Heider and Rein (apud DIAS; CASSAR, 2005, p.224)

Dessa forma, podemos dizer que a internet vem tornando-se peça fundamental nas relações empresa/consumidor, o surgimento das redes sociais também foi uma ferramenta muito importante de divulgação, ainda 
assim os websites podem absorver um maior número de conteúdos para definir uma viagem.

\section{Ecomarketing como vantagem competitiva}

Todos os dias nos noticiários, jornais, revistas, internet e até mesmo em nosso cotidiano presenciamos evidências dos impactos ambientais do modo de vida capitalista e globalizado, esses impactos negativos tomaram tanta proporção que grupos como o Greenpeace e SOS Mata Atlântica ganharam nos últimos anos grande visibilidade, disseminando os valores da Ecologia.

Lowy (2005) defende a ecologia como passo importante na formação de uma sociedade mais preocupada com o planeta, ele vê a sustentabilidade não como proteção apenas às gerações futuras, mas também a presente, e assim justifica o crescimento de ideias ambientalistas no mundo.

A grande contribuição da ecologia foi, e ainda é, fazer-nos tomar consciência dos perigos que ameaçam o planeta em consequência do atual modo de produção e consumo. $O$ crescimento exponencial das agressões ao meio ambiente, a ameaça crescente de uma ruptura do equilíbrio ecológico configura um cenário-catástrofe que põe em questão a própria sobrevivência da vida humana. Confrontamo-nos com uma crise de civilização que exige mudanças radicais (LOWY, 2005, p.45).

Assim, iniciou-se uma corrida a favor do meio ambiente, as questões socioambientais ganharam um destaque em discussões mundiais e com isso o surgimento de termos como: Desenvolvimento Sustentável, Economia Verde, Ecomarketing, Marketing Ecológico e muitos outros, como parte negativa pode haver uma banalização do verdadeiro sentido dessas palavras, o que realmente elas sustentam pode se tornar apenas moda e temas de debates que não tenham resultados concretos de conservação, por exemplo, um Ecomarketing "encenado", apenas para deixar a empresa mais atrativa aos clientes.

\footnotetext{
Diante disso, surge a figura do consumidor verde, que é aquele que considera, no processo de compra, a variável do meio ambiente, ou seja, a sua escolha, pondera se o produto é ambientalmente correto e não prejudicial ao ambiente. Portanto, há uma transferência do ônus da responsabilidade ambiental à sociedade, tendência esta que consolida-se no consumidor verde através de sua exigência pela produção limpa (DEMBROWSKI; HANMER-LLOYD, 1994 apud FREITAS-DA-COSTA; SILVA 2017).
}

Mesmo assim, os benefícios do crescimento do ambientalismo como uma inovadora ideologia social, são muitos superiores as suas desvantagens, as grandes empresas já estão percebendo certa pressão social para 
mudanças de atitude e essas atitudes são tratadas como um diferencial para um mercado de consumo com maior preocupação ambiental.

Ainda em relação ao Ecomarketing, Torres (2015, p. 09) afirma que

- Eco-marketing permitirá explorar comportamentos e atitudes ecologicamente corretos, de rejeição do progresso como argumento de preservação do ambiente, que caracterizam muitos grupos de ambientalistas, ecologistas ou o simples consumidor "verde". Esta tendência criará um grande potencial para o desenvolvimento de empresas e produtos "verdes" (p.e. vestuário, alimentos, combustíveis, turismo), perspectivando-se um futuro promissor e um desenvolvimento sustentável para a eco-indústria

A vantagem competitiva se mostra nesse aspecto, para Motta e Oliveira (2007, p.51) a vantagem competitiva do Marketing é quando

a estratégia de diferenciação conduz a empresa a buscar obter vantagem por meio de ofertas altamente valorizadas pelos consumidores, mesmo que mais custosas. O custo maior não é problema, porque os consumidores permitem-se pagar um preço-prêmio por produtos que são percebidos como mais capazes de satisfazer suas necessidades, o que não significa que se possa descuidar da estrutura de custos, pois isso comprometeria os resultados da empresa. Marketing é a principal forma de obtenção de vantagem competitiva através da diferenciação.

Esse custo é outra questão a ser abordado, para May (2010) o atendimento a normas ambientais, incorporação de tecnologias e gestão ambiental poderia implicar em altos custos e elevados investimentos que acabavam sendo repassados aos clientes em forma de preços mais caros, contudo o autor afirma que com o passar do tempo às experiências bem sucedidas provaram que na verdade ocorreu uma economia de recursos, consequentemente, uma redução dos custos por uma gestão ambiental racionalizada, melhor aproveitamento dos insumos e diminuição de desperdícios, porém, esse retorno não é em curto prazo.

Lima et al. (2010) sugerem criatividade e inovação nesse processo, atitudes pequenas também podem render uma boa redução de despesas na empresa e uma melhor visão da mesma no mercado, somente empresas que não conseguem atentar para os benefícios dessas ações e divulgação das mesmas, acabam acreditando que não terão retornos financeiros, o que os exemplos evidenciam exatamente o contrário, em outras palavras, as ações de gestão ambiental e Marketing verde são extremamente rentáveis e econômicas para as empresas que precisam abrir os olhos para essa nova realidade. 


\section{Método de trabalho e pesquisa}

As metodologias utilizadas foram o levantamento bibliográfico e estatístico e uma pesquisa exploratória que foi realizada em dois momentos.

No primeiro momento foi definida a população da pesquisa através do Cadastur, Programa Federal do Ministério do Turismo que faz um inventário de empresas relacionadas com Turismo. O site do Cadastur disponibiliza informações das empresas de forma acessível na internet, funcionando como uma importante ferramenta para turistas programarem suas próprias viagens entrando em contato com a própria empresa.

No Cadastur, estão cadastradas na cidade de Parnaíba 18 agências de turismo e 20 meios de Hospedagens, as empresas foram enumeradas por letras e dispostas em duas tabelas com cinco informações a serem analisadas por método de observação informal: 1. Site não encontrado, para sites que não encontramos em funcionamento, podendo não existir pela dificuldade de encontrá-los; 2. Site Atualizado, para sites encontrados com informações ou postagens recentes ou em até seis meses; 3. Forte presença de Ecomarketing, para sites que divulgam com detalhes suas ações e/ou prêmios e selos de atividades sustentáveis; 4. Pouca presença de Ecomarketing, para empresas com pequenas menções sobre o tema ao longo dos textos; 5. Nenhuma presença de Ecomarketing, onde na maioria dos casos os sites nem possuem uma boa apresentação.

No segundo momento, foi aplicado um questionário (Apêndice A) com cinco questões numa amostra de seis agências e seis meios de hospedagens, procurando escolher aquelas que possuíam sites mais estruturados, as questões abordadas são: $O$ gestor da empresa conhece 0 termo Ecomarketing ou Marketing Ecológico? A empresa tem um setor de marketing definido? A empresa utiliza estratégias de Ecomarketing? Se "sim" quais? Quais mídias a empresa utiliza para divulgação de seus serviços? As perguntas buscavam investigar se empresários e gestores conhecem as estratégias ecológicas.

\section{Resultados e discussões}

As agências de turismo e os meios de hospedagem tiveram resultados diferentes e irão ser tratados separadamente, foram formuladas duas tabelas para organização de dados obtidos. A Tabela 2 trata da investigação em sites das agências de turismo e a Tabela 3 trata da investigação dos sites dos meios de hospedagens conforme segue:

Tabela 2: Tabela de investigação dos sites das agências.

Table 2: Investigation table of agencies' websites.

\begin{tabular}{|l|c|c|c|c|c|c|c|c|c|c|c|c|c|c|c|c|c|c|c|}
\hline Empresa & A & B & C & D & E & F & G & H & I & J & K & L & M & N & O & P & Q & R \\
\hline SiteNão Encontrado & & & & & & X & X & & X & X & X & & X & X & X & X & X & X \\
\hline Site Atualizado & X & X & X & X & X & & & X & & & & X & & & & & & \\
\hline Forte Presença de EcoMarketing & & & & & & & & & & & & & & & & & & \\
\hline Pouca Presença de EcoMarketing & $\mathrm{X}$ & $\mathrm{X}$ & $\mathrm{X}$ & $\mathrm{X}$ & $\mathrm{X}$ & & & $\mathrm{X}$ & $\mathrm{X}$ & & & $\mathrm{X}$ & & & & & & \\
\hline Nenhuma Presença de EcoMarketing & & & & & & $\mathrm{X}$ & $\mathrm{X}$ & & & $\mathrm{X}$ & $\mathrm{X}$ & & $\mathrm{X}$ & $\mathrm{X}$ & $\mathrm{X}$ & $\mathrm{X}$ & $\mathrm{X}$ & $\mathrm{X}$ \\
\hline
\end{tabular}


Tabela 3: investigação dos sites dos meios de hospedagens.

Table 3: investigation of the sites of the means of lodging.

\begin{tabular}{|l|c|c|c|c|c|c|c|c|c|c|c|c|c|c|c|c|c|c|c|c|}
\hline Empresa & $\mathrm{A}$ & $\mathrm{B}$ & $\mathrm{C}$ & $\mathrm{D}$ & $\mathrm{E}$ & $\mathrm{F}$ & $\mathrm{G}$ & $\mathrm{H}$ & $\mathrm{X}$ & $\mathrm{J}$ & $\mathrm{K}$ & $\mathrm{L}$ & $\mathrm{M}$ & $\mathrm{N}$ & $\mathrm{O}$ & $\mathrm{P}$ & $\mathrm{Q}$ & $\mathrm{R}$ & $\mathrm{S}$ & $\mathrm{T}$ \\
\hline Site Nắo Encontrado & & & & & & & & $\mathrm{X}$ & & $\mathrm{X}$ & $\mathrm{X}$ & $\mathrm{X}$ & & $\mathrm{X}$ & & $\mathrm{X}$ & $\mathrm{X}$ & $\mathrm{X}$ & & \\
\hline Site Atualizado & $\mathrm{X}$ & $\mathrm{X}$ & $\mathrm{X}$ & $\mathrm{X}$ & $\mathrm{X}$ & $\mathrm{X}$ & $\mathrm{X}$ & & $\mathrm{X}$ & & & & $\mathrm{X}$ & & $\mathrm{X}$ & & & & $\mathrm{X}$ & $\mathrm{X}$ \\
\hline Forte Presença de EcoMarketing & & & $\mathrm{X}$ & & & & & & & & & & & & & & & & & \\
\hline Pouca Presença de EcoMarketing & & $\mathrm{X}$ & & $\mathrm{X}$ & $\mathrm{X}$ & & $\mathrm{X}$ & & & & & & $\mathrm{X}$ & & $\mathrm{X}$ & & & & $\mathrm{X}$ & \\
\hline Nenhuma Presença de EcdMarketing & $\mathrm{X}$ & & & & & $\mathrm{X}$ & & $\mathrm{X}$ & $\mathrm{X}$ & $\mathrm{X}$ & $\mathrm{X}$ & $\mathrm{X}$ & & $\mathrm{X}$ & & $\mathrm{X}$ & $\mathrm{X}$ & $\mathrm{X}$ & & $\mathrm{X}$ \\
\hline
\end{tabular}

As tabelas ilustrando o primeiro momento dessa pesquisa contemplam cinco informações que serão tratadas sobre três perspectivas para uma melhor explanação das análises das informações: 1. Site não encontrado, para sites que não encontramos em funcionamento, podendo não existir pela dificuldade de encontra-lo; 2. Site Atualizado, para sites encontrados com informações ou postagens recentes ou em até seis meses; 3. Presença de Ecomarketing, com indicadores de forte, pouca ou nenhuma presença de iniciativas ecológicas. Foi percebido uma diferença de resultados entre agências e meios de hospedagem e serão tratados separadamente.

Durante a pesquisa verificou-se que $61 \%$ dos sites de agências de viagens informados no Cadastur não foram encontrados. Essas empresas não possuem site ou não disponibilizaram um site de fácil acesso na rede de internet, ou seja, apenas 39\% das empresas estudadas possuem um site de fácil acesso. Foi identificada também, que apenas 39\% das empresas pesquisadas possuem sites atualizados.

Quanto a presença de Ecomarketing nos sites, não foi identificado fortemente em seus sites, $44 \%$ apresentaram alguma presença, apenas em frases isoladas mencionando que tinham alguma preocupação socioambiental, porém não informava detalhes de que práticas lhe dariam tal característica, a maioria, $55 \%$ nem mencionou sobre o assunto abordado em seus textos, inclusive esses mesmos 55\% apresentavam sites apenas descritivo dos pacotes e informações de contatos sem nenhuma estratégia diferencial. Porém, o Ecomarketing ou Marketing Verde segundo Buogo, Zilli e Vieira (2015, p. 61):

Marketing Verde é um instrumento mercadológico que utiliza benefícios ambientais proporcionados por um produto, assim se destacando a frente dos concorrentes. Além de vários benefícios esta ferramenta ajuda a melhorar a imagem da organização perante a sociedade, nos setores [...] fica evidente a questão ambiental, no entanto organizações de ambos os segmentos utilizam ações de marketing verde para resolver este problema.

Para os meios de hospedagens, a pesquisa verificou uma situação um pouco melhor que nas agências, onde que $40 \%$ dos sites não foram encontrados, com $60 \%$ de sites encontrados e de fácil acesso na internet. Quanto à atualização, foi identificado que $60 \%$ dos sites estão em funcionamento e atualizados. A pesquisa mostrou apenas um meio de 
hospedagem com forte presença de Ecomarketing com 5\%, para pouca presença $35 \%$ e para nenhuma presença $60 \%$.

$\mathrm{Na}$ pesquisa foi observado um desinteresse das empresas turísticas na utilização de sites para divulgação de seus serviços. Apenas uma empresa apresentou medidas de Ecomarketing em seu website, onde ela informa todas as ações sustentáveis, como aquecedores solares e selos de sustentabilidade recebidos e comprovam através de seus prêmios e fotos disponibilizadas no seu website. Apresentando dados que não são compatíveis com a contemporaneidade, como cita Perinotto (2013, p. 13):

As tecnologias midiáticas, por sua vez, deixam de ser observadas como suportes técnicos para a realização da comunicação e passam a ser observadas como mídias propriamente, sendo imprescindíveis para a realização de determinadas relações sociais. Com isso, parece ser cada vez mais tênue a diferença entre as relações que acontecem face a face e as relações mediadas por tecnologias midiáticas.

As informações observadas indicaram que a maioria das empresas turísticas de Parnaíba não possuem websites na internet, porém as que o possuem, sendo aproximadamente $40 \%$ os mantém atualizados e funcionando. Assim destoando do que observa nas pesquisas atuais de turismo em que se percebe, conforme afirma Perinotto (2013, p.15) que "na relação turista e empresa, consumidor e vendedor, turista e turista, empresa e empresa, a Internet entra como uma nova ferramenta de comunicação".

No segundo momento, foi aplicado um questionário (Apêndice A) com cinco questões numa amostra de seis agências e seis meios de hospedagens, procurando escolher aquelas que possuíam sites mais estruturados, as questões abordadas são: $O$ gestor da empresa conhece 0 termo Ecomarketing ou Marketing Ecológico? A empresa tem um setor de marketing definido? A empresa utiliza estratégias de Ecomarketing? Se "sim" quais? Quais as mídias a empresa utiliza para divulgação de seus serviços?

As perguntas buscavam investigar se empresários e gestores conhecem as estratégias ecológicas. Essas perguntas buscavam investigar se empresários e gestores conhecem algumas estratégias ecológicas e essas questões vão ser explanadas através dos cinco gráficos abaixo:

$\mathrm{Na}$ primeira questão $75 \%$ das empresas disseram conhecer o termo Ecomarketing ou Marketing Ecológico, 25\% disseram não conhecer o termo.

Em seguida foi perguntado se a empresa possui um setor de Marketing definido e 17\% responderam que sim e $83 \%$ disseram que não possuem. Na pergunta posterior $50 \%$ das empresas entrevistadas disseram que utilizam estratégias de Ecomarketing, as outros 50\% disseram que não.

A quarta pergunta deveriam ter seis respostas, pois dependiam da terceira, mas $25 \%$ das empresas mencionaram ações de marketing ecológico que praticam, como o cuidado com o lixo e a preocupação em 
informar ao cliente sobre a importância da sustentabilidade, ou até mesmo apartamentos ligados com energia solar. Desse modo, acompanhando o que se entende por Marketing, conforme Vidal (2012, p. 32):

Fazer marketing não é apenas divulgar as qualidades da empresa e com isso vender mais; é, acima de tudo, a busca sempre do melhor, seja atendimento, preço, qualidade; é tentar corrigir os erros e melhorar aquilo que já era bom e conceituado. Dessa forma, aquela empresa que se preocupa com a satisfação do consumidor, deve, de fato, promover seu marketing, gerando assim uma competitividade, o que favorece ainda mais o consumidor e seu poder de escolha. Ou seja, o consumidor é peça chave na busca pela sustentabilidade, já que seu poder de decisão é fundamental para acirrar a disputa entre as empresas que farão seu melhor para conquistar os clientes contemporâneos.

A quinta pergunta investigava quais as mídias mais usadas pelas empresas que foram redes sociais em primeiro com $28 \%$, depois sites com $25 \%$, em terceiro folders com $23 \%$, também há revistas com $12 \%$, em quinto o item outros, com 9,5\% (jornais, feiras e eventos, links patrocinados e emails), além disso, em sexto ficou rádio com 2,5\%, e por fim, nenhuma empresa informou utilizar a televisão como mídias de divulgação. Corroborando esses dados, Cantinho, Correia e Ramos (2016, p. 29) afirmam que

os meios sociais digitais trouxeram uma mudança ao nível da comunicação, com possibilidade de as empresas criarem e gerirem a sua própria publicidade em meios gratuitos, contrariamente aos habituais meios publicitários, nos quais é necessário despender elevadas quantias monetárias. Além disso, os meios sociais digitais permitem que a informação seja disponibilizada de uma forma mais direcionada ao público-alvo e à sua rede de contatos.

Percebe-se uma problemática, sites e redes sociais estão em primeiro mencionados. Porém, a maioria das empresas nem possuem Websites, ou não sabem como funciona, e nem sua importância. Como observou-se, a internet é fundamental na comunicação turística de destinos e serviços. As empresas também informaram um dado importante de divulgação, os eventos e as revistas.

Nota-se com isso que a maioria das empresas não possui um setor de Marketing definido, possivelmente desconheçam a importância desse setor no turismo, $75 \%$ das empresas alegaram conhecer o termo Ecomarketing, porém apenas $50 \%$ indicaram implementações em suas organizações. Nesse sentido, 
São diversos os benefícios que podem ser adquiridos com a implantação do marketing verde, pois crescentes cada dia os consumidores que optam por essa postura e a estão tornando um hábito no critério de escolha de um produto. No mercado competitivo o que vale é a diferenciação de produto, e para garantir certo poder de mercado, a empresa terá de lançar mão de investimentos, e quando estes são atribuídos ao marketing verde, pode afetar inteiramente o consumidor, pois a urgência ambiental ganhou notoriedade e a crescente conscientização ecológica gera oportunidades para as empresas (FELIZOLA; COSTA, 2010 apud BUOGO; ZILLI; VIEIRA, 2015, p. 65).

O turismo na cidade de Parnaíba enfrenta muitos desafios como sazonalidade e períodos de alta visitação muito curtos, porém existem muitas perspectivas de desenvolvimento do turismo na cidade como o funcionamento de um curso de turismo na Universidade Federal do Piauí, a recente abertura de voos regulares no aeroporto da cidade, entre outras medidas tomadas parecem mostrar que a os empresários da cidade devem se preparar para receber cada vez mais turistas.

\section{Considerações finais}

As estratégias de Ecomarketing não suprirão todas as lacunas existentes, são apenas alternativas que devem ser aliadas às empresas nessa preparação. Afinal ela tem que ser cumprida para se consolidar, por que caso ela seja apenas encenada como forma de falsa promoção, essa empresa corre o risco de perder sua credibilidade e com isso seus clientes. Para o turismo em áreas naturais, nada adianta falar de Ecomarketing sem realmente realizar verdadeiramente suas propostas.

Quanto à pesquisa sobre o Ecomarketing na Web como estratégia competitiva nas empresas turisticas em Parnaíba $(\mathrm{PI})$, foi identificado que mais da metade dos casos estudados nem possuem um site de fácil acesso disponível em rede, sendo necessários futuros aprofundamentos de pesquisa para investigar o motivo desse desinteresse. Quanto a presença de Ecomarketing apenas uma obedeceu o proposto pelo termo, em média $40 \%$ dessas empresas falaram um pouco sobre sustentabilidade em seus textos de divulgação, o que mostram que ao menos eles iniciaram uma preocupação em mostrar esse tema de alguma forma, mesmo assim mais da metade das empresas, aproximadamente $58 \%$ não despertou para as estratégias de desenvolvimento de seus estabelecimentos.

É perceptível diante do estudo o despreparo de uma grande parte de empresários parnaibanos em entender que o turismo é muito dinâmico e precisa estar pronto para os novos desafios que surgem todos os dias. Do turismo dependem as tendências mundiais e essas empresas precisam acompanhá-las para sobreviver e ter desenvolvimento considerado ao invés de crescimento sem nenhum planejamento futuro. 


\section{Referências}

BRASIL - MINISTÉRIO DO TURISMO. Hábitos de consumo do turismo do brasileiro. 2009. Disponível em:

http://www.dadosefatos.turismo.gov.br/export/sites/default/dadosefatos/dema nda turistica/pesquisa habitos/Download pesquisa habitos/13.11.09 Pesq uisa Hxbitos 2009.pdf. Acesso em: 07/02/2014.

BRASIL - Cadastur. (s/d). Disponível em:

http://www.cadastur.turismo.gov.br/cadastur/index.action\#>. Acesso em: 28/01/2014.

BUOGO, F.P.; ZILLI, J.C.; VIEIRA, A.C.P. Marketing Verde Como Diferencial Competitivo: Um Estudo Em Uma Indústria Química Do Sul De Santa Catarina. RECC - Revista Eletrônica Científica do CRA-PR, v. 2, n. 2, p. 60-73, 2015.

CANTINHO, G.M.R., CORREIA, M.B.; RAMOS, C.M.Q. As redes sociais online nos hotéis de 4 e 5 estrelas do Algarve. Tourism and Hospitality International Journal, v.7, n.1, pp.27-48. 2016.

DIAS, R.; CASSAR, M. Fundamentos do marketing turístico. São Paulo: Pearson Prentice Hall, 2005.

FREITAS-DA-COSTA, M.; SILVA, N.S.L. Marketing verde e consciência o consumidor: realidade ou utopia de consumo? XIII SemeAd - Seminários em Administração, 2010.

LIMA, G.B. et al. Marketing verde e gestão ambiental nas organizações: estudo teórico-conceitual. Anais do IX Convibra Administração - Congresso Virtual Brasileiro de Administração, 2012.

LÖWY, M. Ecologia e socialismo. São Paulo: Cortez, 2005.

MAY, P.H. Economia do meio ambiente: teoria e prática. $2^{\underline{a}}$ ed. Rio de Janeiro: Elservier, 2010.

MOLINA, S. Turismo e Ecologia. Baurú, SP: EDUSC, 2001.

MOTTA, S. L. S \& OLIVEIRA, B. (2007) O marketing ecológico como vantagem competitiva. Revista de Gestão USP, v.14, n.2, pp.49-59, 2017.

NIELSEN, C. Turismo e mídia: o papel da comunicação na atividade turística. São Paulo: Contexto, 2002.

PERINOTTO, A. R. C. Investigando a comunicação turística de Parnaíba/PIBrasil: Internet e redes sociais, descrição e análise. Revista de Investigación em Turismo y Desarrollo Local - TURyDES. v,6, n.15 (diciembre/dezembro 2013). 2013.

TOMIKAWA, J.M. Marketing turístico e internet: uma análise dos sites oficiais de turismo dos estados brasileiros. Brasília: UNB, 2009.

TORRES, A. Pós-modernidade e Consumo: Desafios ao Neo-Marketing. European Journal of Applied Business Management, v.1, n.2, 2015, pp. 2015. 
VIDAL, A.C. Marketing ambiental e consumo sustentável: a tendência de empresários e consumidores rumo ao mercado sustentável. Trabalho de Conclusão de Curso de Pós-graduação em Análise Ambiental e Desenvolvimento Sustentável Centro Universitário de Brasília (UniCEUB/ICPD), 2012.

Mayara Maia Ibiapina: Universidade Federal do Piauí, Parnaíba, PI, Brasil.

E-mail:myaramaia@hotmail.com

Link para o currículo Lattes: http://lattes.cnpq.br/4035485473219885

Thaís Mayara Paes de Lima: Universidade Federal do Piauí, Parnaíba, PI, Brasil. E-mail: thaismayarasrn@hotmail.com

Link para o currículo Lattes: http://lattes.cnpq.br/8469270511796562

André Riani Costa Perinotto: Universidade Federal do Piauí, Parnaíba, PI, Brasil. E-mail: perinotto@ufpi.edu.br

Link para o currículo Lattes: http://lattes.cnpq.br/9146688925419493

Data de submissão: 28 de abril de 2015

Data de recebimento de correções: 05 de maio de 2017

Data do aceite: 05 de maio de 2017

Avaliado anonimamente 